\title{
Adolescents' explicit and implicit evaluations of hypothetical and actual peers with different bullying participant roles
}

\author{
J. Loes Pouwels*, Tessa A.M. Lansu, Antonius H.N. Cillessen \\ Behavioural Science Institute, Radboud University, 6525 HR Nijmegen, The Netherlands
}

\section{A R T I C L E I N F O}

\section{Article history:}

Received 8 June 2016

Revised 13 February 2017

Available online 19 March 2017

\section{Keywords:}

Bullying

Peer Victimization

Attitudes

Implicit

Participant roles

Social cognition

\begin{abstract}
A B S T R A C T
This study examined how adolescents evaluate bullying at three levels of specificity: (a) the general concept of bullying, (b) hypothetical peers in different bullying participant roles, and (c) actual peers in different bullying participant roles. Participants were 163 predominantly ethnic majority adolescents in The Netherlands (58\% girls; $M_{\text {age }}=16.34$ years, $S D=0.79$ ). For the hypothetical peers, we examined adolescents' explicit evaluations as well as their implicit evaluations. Adolescents evaluated the general concept of bullying negatively. Adolescents' explicit evaluations of hypothetical and actual peers in the bullying roles depended on their own role, but adolescents' implicit evaluations of hypothetical peers did not. Adolescents' explicit evaluations of hypothetical peers and actual peers were different. Hypothetical bullies were evaluated negatively by all classmates, whereas hypothetical victims were evaluated relatively positively compared with the other roles. However, when adolescents evaluated their actual classmates, the differences between bullies and the other roles were smaller, whereas victims were evaluated the most negatively of all roles. Further research should take into account that adolescents' evaluations of hypothetical peers differ from their evaluations of actual peers.
\end{abstract}

(ㄷ) 2017 Elsevier Inc. All rights reserved.

\footnotetext{
* Corresponding author.

E-mail address: j.pouwels@psych.ru.nl (J.L. Pouwels).
} 


\section{Introduction}

Bullying is a major problem in schools. It is associated with increased risks for psychosocial maladjustment for both bullies and victims (Kaltiala-Heino, Rimpelä, Rantanen, \& Rimpelä, 2000; Nansel et al., 2001; Reijntjes, Kamphuis, Prinzie, \& Telch, 2010). Bullying takes place when individuals or groups repeatedly and over time attack, humiliate, or exclude victims who cannot defend themselves (Salmivalli, 2010; Solberg \& Olweus, 2003). Bullying is a group process in which children can have different roles (Salmivalli, Lagerspetz, Björkqvist, Österman, \& Kaukiainen, 1996). In addition to the bullies and victims, assistants actively join in by helping the bullies, reinforcers give bullies positive feedback (e.g., by providing an audience or laughing), defenders try to stop the bullying or comfort the victims, and outsiders refrain from getting involved.

Previous studies placed much emphasis on how youths evaluate bullying behavior because this is expected to be an important determinant of their own behavior in bullying situations (see, e.g., Almeida, Correia, \& Marinho, 2010; Andreou, Vlachou, \& Didaskalou, 2005; Boulton, Trueman, \& Flemington, 2002; Rigby, 2005; van Goethem, Scholte, \& Wiers, 2010). However, children's role in bullying situations is not always in line with their attitudes toward bullying (Salmivalli \& Voeten, 2004). To date, most studies have examined children's evaluations of the general concept of bullying, but evaluations of the specific participant roles have not been examined systematically yet. The current study went beyond evaluations of the general concept of bullying by also examining youths' attitudes toward specific roles and, furthermore, how these attitudes depend on their own bullying role. When evaluating the six participant roles, evaluations of hypothetical peers may very well differ from evaluations of actual classmates in these roles. Therefore, we compared adolescents' evaluations of the participant role behaviors in hypothetical situations (hypothetical peers) with their evaluations of the same behaviors in their actual classmates (actual peers). In addition, we studied the difference between explicit and implicit evaluations of bullying involvement by comparing explicit and implicit evaluations of hypothetical peers in each bullying role. Differences between evaluations of hypothetical and actual peers and between explicit and implicit evaluations may help us to understand why adolescents' own bullying involvement is often inconsistent with their attitudes. The results may contribute to anti-bullying programs by increasing adolescents' awareness of potential mismatches between their general evaluations of bullying (role) behaviors and their evaluations of actual peers who engage in them.

\section{Adolescents' evaluations of the general concept of bullying}

Most children and adolescents evaluate bullying negatively and intend to support victims of bullying (Menesini et al., 1997; Salmivalli \& Voeten, 2004; van Goethem et al., 2010). However, only $20 \%$ of adolescents seem to behave according to their attitude and actually defend or comfort victims of bullying (Salmivalli, 2010). In addition, the link between adolescents' evaluations of bullying and their own bullying behavior is weak to moderate at best (Menesini et al., 1997; Rigby, 2004; Scholte, Sentse, \& Granic, 2010). This discrepancy may be explained by the way studies have examined adolescents' evaluations of bullying.

In most studies, adolescents' evaluations of bullying were measured with the "attitude toward bullying" scale (Salmivalli \& Voeten, 2004; Scholte et al., 2010) or the "attitudes toward victims" scale (Rigby \& Slee, 1991). In these scales, adolescents evaluate multiple aspects of bullying such as rejection of vulnerable peers, cognitive or affective empathy toward victims, approval of pro-bullying behavior, intervening in bullying situations, and support for victims. Answers to such items usually are aggregated to one score assuming a one-factor scale. We define the evaluations of these aspects of bullying in the attitude toward bullying scale as "evaluations of the general concept of bullying." A potential problem of those scales is that they do not take into account that adolescents may evaluate different aspects of bullying differently.

\section{Adolescents' evaluations of hypothetical peers with different participant roles}

Although most adolescents have negative attitudes toward the general concept of bullying, a number of them still show pro-bullying behaviors. This may be explained by adolescents' evaluations of 
specific peers in certain bullying roles. How adolescents evaluate the bullying participant roles has been examined by asking them to evaluate participant role behaviors in hypothetical situations (Almeida et al., 2010; Boulton, Lloyd, Down, \& Marx, 2012; Gini, Pozzoli, Borghi, \& Franzoni, 2008). Research has shown that adolescents evaluate victims more favorably than bullies (Boulton et al., 2012) and that their attitudes toward bullies and defenders are negatively related (Almeida et al., 2010). Adolescents also disapproved of pro-bullying behavior and endorsed prosocial behavior of hypothetical bystanders toward victims in vignette stories (Gini, Pozzoli, et al., 2008). These results indicate that adolescents explicitly seem to evaluate various bullying behaviors differently. However, research has not systematically compared adolescents' evaluations of all six participant roles. This was done in this study, and we hypothesized that adolescents would evaluate hypothetical defenders, outsiders, and victims more positively than hypothetical bullies.

\section{Adolescents' evaluations of actual peers with different participant roles}

As indicated, adolescents' explicit evaluations of different bullying behaviors have typically been studied with hypothetical scenarios (Gini, Pozzoli, et al., 2008). In these studies, adolescents usually were not instructed to take in mind specific peers who behaved according to each role. Thus, they based their evaluations purely on the behavior described in the scenarios. However, adolescents may disapprove of a behavior but still positively evaluate the peer who engages in the behavior. Adolescents' classmates not only show bullying behaviors in school but also display a range of other behaviors that affect how their peers see them. For example, adolescent bullies and followers are seen not only as aggressive but also as popular by their peers (Peeters, Cillessen, \& Scholte, 2010; Pouwels, Lansu, \& Cillessen, 2016). They also score high on peer-valued characteristics such as leadership, attention, and humor (Pouwels et al., 2016; Vaillancourt \& Hymel, 2006). The popularity and peervalued characteristics of bullies and followers may compensate for their bullying behavior. Victims also display other behaviors that are not directly related to their victim role but that affect how their peers see them. Actual victims are often rejected, low in prosocial behavior, or reactively aggressive (Pouwels et al., 2016). Such characteristics may reduce adolescents' sympathetic attitudes toward actual victims.

There is also some evidence that adolescents justify bullying when they are asked to think back to episodes that they experienced or witnessed themselves (Hara, 2002). For example, victims are blamed for being bullied and adolescents deny that they were harmed. Thus, although adolescents tend to negatively evaluate bullying behavior, they may use several strategies to justify bullying in their own classrooms (Salmivalli, 2010). Together, this suggests that the level at which bullying involvement is specified (e.g., the construct in general, hypothetical bullying involvement, actual bullying involvement) matters for its evaluation. This assumption was tested in this study by examining adolescents' evaluations of hypothetical peers as well as actual peers in each participant role. Evaluations of hypothetical peers who just acted in line with a particular participant role in a bullying situation are assumed to reflect evaluations of the behavior related to the role. Evaluations of actual peers that are made without prompting adolescents to think about them in bullying situations are assumed to reflect evaluations of actual classmates in each participant role.

\section{Implicit evaluations of different bullying participant roles}

In addition to the distinction between hypothetical and actual peers, it is relevant to distinguish explicit and implicit evaluations of bullying. Most studies have examined adolescents' explicit evaluations of the bullying roles. Explicit evaluations are controlled, deliberate, self-reported, and made with awareness (Gawronski \& Bodenhausen, 2006; Strack \& Deutsch, 2004). Implicit evaluations are automatic, nondeliberate, and outside of one's control (Gawronski \& Bodenhausen, 2006; Strack \& Deutsch, 2004). Implicit evaluations can be inferred from reaction time tasks such as the implicit association task (IAT; Greenwald \& Banaji, 1995). The IAT captures a person's automatic evaluative associations with a certain concept of which the person often is unaware (De Houwer, 2006).

Implicit evaluations may play a role when adolescents witness bullying. According to the models by Strack and Deutsch (2004) and Gawronski and Bodenhausen (2006), spontaneous or automatic 
reactions are more likely to be influenced by implicit evaluations, whereas controlled reactions are more likely to be influenced by explicit evaluations. The MODE model states that motivation and opportunity are needed to process information in a deliberative way rather than an automatic way (Fazio, 1990; Olson \& Fazio, 2009). People need to be motivated for deliberative processing. If people are motivated, they also need to have the opportunity to act on their explicit attitudes. Because cognitive resources are limited, fatigue and distraction may restrict the opportunity to process information deliberatively. Moreover, because cognitive processing takes time, initial responses may be driven by implicit evaluations (Olson \& Fazio, 2009).

Similarly, when adolescents witness bullying, their initial response may be driven by their implicit evaluations of bullying, victimization, and defending. For example, their implicit evaluations may determine whether they initially show a facial expression that is disapproving of the bully's behavior. After this primary response, adolescents have time to think about their behavioral response. Motivation and opportunity determine to what extent adolescents' secondary responses will be influenced by their explicit evaluations of, for example, the bully. Thus, whereas some adolescents may initially disapprove of bullying, after a few seconds they may provide positive feedback to a bully if they are motivated to make a positive impression on this peer and have sufficient cognitive resources to act on this motivation.

Research on implicit evaluations of bullying is scarce. Two studies have assessed implicit associations with the general concepts of bullying and victimization (Rosen, Milich, \& Harris, 2007; van Goethem et al., 2010). In these studies, adolescents' experiences of victimization were associated with stronger implicit associations of themselves with the role of victim, indicating that their victimization may have become part of their self-concept (Rosen et al., 2007). Moreover, adolescents' implicit evaluations of bullying predicted their bullying behavior when they explicitly evaluated bullying positively (van Goethem et al., 2010). These studies show that implicit associations with bullying and victimization in general may be related to bullying, but we do not know yet how adolescents implicitly evaluate each bullying participant role.

There is some evidence that adolescents' implicit evaluations of peers depend on their peers' reputations. Lansu, Cillessen, and Karremans (2012) found that popular peers, who tend to engage in aggressive behavior and bullying (Cillessen \& Rose, 2005), were positively evaluated at an explicit level but negatively at an implicit level. This is in line with research showing that negative information influences automatic processing more strongly than positive information (Dijksterhuis \& Aarts, 2003; Ito, Larsen, Smith, \& Cacioppo, 1998). The negative characteristics of popular peers, such as their display of aggression or bullying, may affect adolescents' implicit evaluations. The positive characteristics of popular adolescents, such as their influence and visibility, may have a stronger impact on adolescents' explicit evaluations. In line with this, it may be that adolescents evaluate the bully role more negatively at the implicit level than at the explicit level. We tested this assumption by comparing explicit and implicit evaluations of hypothetical peers in each bullying participant role.

\section{Adolescents' own participant role involvement predicting bullying evaluations}

The second aim of this study was to examine to what extent adolescents' own bullying involvement is associated with their evaluations of bullying in general, of hypothetical peers in each bullying role, and of actual peers in each bullying role. Peer evaluations are driven not only by the people being evaluated but also by the people making the evaluations. For example, it has already been shown that victims, defenders, and outsiders evaluate the general concept of bullying more negatively than bullies, assistants, and reinforcers do (Pellegrini, Bartini, \& Brooks, 1999; Salmivalli \& Voeten, 2004). Bullying, reinforcing, or assisting may be rewarding by obtaining higher status in the peer group (Juvonen \& Galván, 2008; Reijntjes et al., 2013). Such rewards may lead bullies and their followers to have more favorable views of the general concept of bullying than defenders, outsiders, and victims do (Pellegrini et al., 1999).

In addition to the general concept of bullying, adolescents' own bullying involvement also may be associated with their evaluations of the participant roles. The similarity/attraction hypothesis states that people evaluate others who are similar to themselves more positively than others who are different from themselves (Byrne, 1971). Indeed, it has been shown that bullies evaluate the bully role more positively than victims do (Menesini et al., 1997). Another study has shown that adolescents' own bullying involvement also affects their implicit peer evaluations of classmates; girls who bully negatively evaluated their 
classmates at an implicit level (Lansu, Cillessen, \& Bukowski, 2013). These findings suggest that adolescents' evaluations of the participant roles may also depend on their own bullying involvement.

\section{The current study}

Most previous studies examined adolescents' evaluations of the general concept of bullying. Although some studies suggest that adolescents may differentiate their evaluations of adolescents in different participant roles (Boulton et al., 2012; Gini, Pozzoli, et al., 2008), a direct comparison of adolescents' evaluations of the six participant roles is lacking. Adolescents' evaluations of the participant roles also may differ depending on whether adolescents are evaluating participant role behavior (hypothetical peers) or their classmates who engage in these behaviors (actual peers) (Salmivalli, 2010). Therefore, the first goal of this study was to examine adolescents' evaluations of bullying at three levels of specificity: the general concept of bullying, hypothetical peers in each participant role, and actual peers in each participant role. In addition to explicit evaluations, examining implicit evaluations of bullying is important to understand bullying behavior (van Goethem et al., 2010). Therefore, we also examined adolescents' implicit evaluations of hypothetical peers.

With regard to the general concept of bullying, we expected that adolescents would evaluate bullying negatively (Menesini et al., 1997; Scholte et al., 2010). Regarding the explicit evaluations of hypothetical peers in the participant roles, we expected that defenders would be evaluated most positively, followed by outsiders and then victims. Bullies and followers were expected to be evaluated least positively (Gini, Pozzoli, et al., 2008). With regard to the evaluations of actual peers, we expected that actual bullies and followers would be evaluated more positively than hypothetical bullies and followers because bullying is associated with high status in the classroom during adolescence (Pouwels et al., 2016). Actual victims were expected to be evaluated more negatively than hypothetical victims because adolescents may blame actual victims for being bullied to justify bullying in their classroom (Salmivalli, 2010). Finally, we expected that bullies and followers in particular would be evaluated negatively at the implicit level because negative information has more impact on automatic processes than positive information does (Dijksterhuis \& Aarts, 2003; Ito et al., 1998).

To meet the second goal of the study, we also examined whether adolescents' evaluations of bullying varied by their own participant role involvement at each level of specificity. With regard to evaluations of the general concept of bullying, we expected that adolescents who are bullies, assistants, or reinforcers would have more positive evaluations of the general concept of bullying than adolescents who are victims, defenders, or outsiders do (Pellegrini et al., 1999; Salmivalli \& Voeten, 2004). We also expected that adolescents' own participant role would be associated with their explicit and implicit evaluations of hypothetical peers and their explicit evaluations of actual peers (Juvonen \& Galván, 2008). In line with the similarity/attraction hypothesis, we hypothesized that adolescents would evaluate hypothetical and actual peers in the same role as themselves most positively (Byrne, 1971).

To address these research questions, data were collected in two phases. Phase 1 consisted of a classroom assessment of participant role involvement and peer liking. A selection of adolescents then participated in Phase 2. This phase consisted of an online assessment in which participants were primed by a video where six cartoon characters were presented, each representing one bullying participant role. Six single-target implicit association tasks (ST-IATs) then measured adolescents' implicit evaluations of the cartoon character in each role. Participants also explicitly evaluated each character. Finally, they completed the Anti-Bullying Attitude Scale to measure their evaluations of the general concept of bullying.

\section{Method}

\section{Participants}

Phase 1 was part of Wave 9 of the Nijmegen Longitudinal Study on infant and child social development in The Netherlands (Pouwels et al., 2016; van Bakel \& Riksen-Walraven, 2002) Data were collected in 63 classrooms, ranging from the 9th to the 12th grades, in 24 secondary schools. The 
average classroom size was 26.10 (range $=13-32$ ). Of the 1650 adolescents in the classrooms, 1477 (90\%) completed all sociometric measures.

At the end of Phase 1, adolescents could indicate their interest in Phase 2 of the study. Of the 1477 adolescents, 474 (32\%) expressed interest in additional information about Phase 2. We invited 284 adolescents to take part in Phase 2 based on their participant roles. We aimed for at least 50 adolescents per role to have comparable group sizes and enough power to compare them on the dependent variables. For some roles, more than 50 adolescents met the criteria. In that case, a random selection was made among those adolescents who received nominations from a relatively high number of classmates. The selection process is presented in Table 1.

Of the 284 adolescents who were invited for Phase 2, 188 adolescents (66\%) gave assent and their parents gave active consent to participate. Due to technical problems, 4 adolescents were not able to complete the online computerized assessment. Data from 16 adolescents were not included in the analyses because they did not pass the manipulation check for the participant roles of the hypothetical peers. An additional 3 adolescents were excluded from the analyses because they made errors in more than $20 \%$ of the trials in the combined blocks of the ST-IATs that measured the implicit evaluations. Another 2 adolescents, 1 bully and 1 victim, were excluded because their explicit evaluation data of actual bullies and victims were missing. Because they were the only bully or victim in their classroom, there were no other classmates with a bully or victim role who they could evaluate. As a result, all analyses were conducted on a sample of 163 adolescents ( $87 \%$ of the Phase 2 sample). Table 2 summarizes the demographics of the participants in Phase 1 and the subsample who participated in both Phase 1 and Phase 2. The ages and ethnic compositions of the total sample and subsample were comparable. The percentage of girls was larger in Phase 2 than in Phase 1. Adolescents from higher educational tracks were more likely to participate in Phase 2 and were overrepresented in this study compared with the national average (Onderwijs in Cijfers, 2014).

\section{Procedure}

In Phase 1, the participant roles of bullying and evaluations of actual peers were measured in a 50min classroom session using laptop computers. Two or three experimenters gave participants instructions in which they guaranteed the confidentiality of their answers and gave a definition of bullying (Solberg \& Olweus, 2003). We provided each student with a mini laptop computer from the university to complete the assessment. We separated desks and placed partitioning screens on each desk to give students privacy when responding to the questionnaire. See Pouwels et al. (2016) for a detailed description of the procedure of Phase 1.

Phase 2 took place within 4 months after the classroom assessment $\left(M_{\text {interval }}=70.56\right.$ days, $S D=20.03$ ). This phase consisted of a 30-min online computerized assessment. We sent the link to this assessment by e-mail, and adolescents were asked to complete the task individually in a quiet space at home. During this assessment, we subsequently examined students' implicit and explicit evaluations of hypothetical peers with different bullying roles and their evaluations of the general concept of bullying, followed by a daily diary part. The daily diary information was not included in the current study. The study was approved by the institutional review board of the university. Adolescents received a voucher of 5 euros as compensation for their participation.

\section{Measures}

\section{Participant roles}

During the classroom assessment, the participant roles of bullying were assessed with the shortened Participant Role Questionnaire (PRQ; Pouwels et al., 2016; Salmivalli \& Voeten, 2004). Adolescents were presented with 15 items describing different ways to behave in bullying situations. They were asked to nominate classmates who fit each description. The shortened PRQ has a 3-item scale for each participant role: bully (e.g., "Who starts bullying?"), assistant (e.g., "Who joins in the bullying when someone else has started it?"), reinforcer (e.g., "Who comes around to watch the situation when someone is being bullied?"), defender (e.g., "Who tries to make the others stop bullying"), and outsider 
Table 1

Participants selected for Phase 2 per role.

\begin{tabular}{|c|c|c|c|c|c|c|c|c|c|c|c|c|c|c|}
\hline & \multicolumn{2}{|c|}{$\begin{array}{l}\text { Total } \\
\text { sample: } \\
\text { Phase } 1\end{array}$} & \multicolumn{3}{|c|}{ Interest: Phase 2} & \multicolumn{3}{|c|}{ Invited: Phase 2} & \multicolumn{3}{|c|}{ Participation: Phase 2} & \multicolumn{3}{|c|}{ Final analyses: Phase 2} \\
\hline & $\begin{array}{l}n \\
\text { total }\end{array}$ & $\begin{array}{l}n \\
\text { girls }\end{array}$ & $\begin{array}{l}n \\
\text { total }\end{array}$ & $\begin{array}{l}\text { \% of total } \\
\text { sample }\end{array}$ & $\begin{array}{l}n \\
\text { girls }\end{array}$ & $\begin{array}{l}n \\
\text { total }\end{array}$ & $\begin{array}{l}\text { \% of total } \\
\text { sample }\end{array}$ & $\begin{array}{l}n \\
\text { girls }\end{array}$ & $\begin{array}{l}n \\
\text { total }\end{array}$ & $\begin{array}{l}\text { \% of total } \\
\text { sample }\end{array}$ & $\begin{array}{l}n \\
\text { girls }\end{array}$ & $\begin{array}{l}n \\
\text { total }\end{array}$ & $\begin{array}{l}\text { \% of total } \\
\text { sample }\end{array}$ & $\begin{array}{l}n \\
\text { girls }\end{array}$ \\
\hline Bully & 138 & 51 & 44 & 32 & 17 & 30 & 22 & 10 & 17 & 12 & 5 & 15 & 11 & 4 \\
\hline Follower & 423 & 133 & 122 & 29 & 43 & 83 & 20 & 26 & 49 & 12 & 19 & 41 & 10 & 17 \\
\hline Defender & 297 & 220 & 122 & 41 & 90 & 66 & 22 & 48 & 48 & 16 & 35 & 47 & 16 & 34 \\
\hline Outsider & 377 & 199 & 112 & 30 & 67 & 63 & 17 & 37 & 43 & 11 & 28 & 39 & 10 & 25 \\
\hline Victim & 161 & 78 & 51 & 32 & 27 & 41 & 25 & 21 & 27 & 17 & 17 & 21 & 13 & 14 \\
\hline No role & 81 & 32 & 23 & 28 & 10 & 1 & 1 & 0 & 0 & 0 & 0 & 0 & 0 & 0 \\
\hline Total & 1477 & 713 & 474 & 32 & 254 & 284 & 19 & 142 & 184 & 12 & 104 & 163 & 11 & 94 \\
\hline
\end{tabular}

Note. We invited 1 adolescent without a role because the adolescent scored high on self-reported victimization, which was the topic of another study.

(e.g., "Who does not take sides with anyone?"). Victimization was examined with 4 additional items (e.g., "Who is victimized?", "Who is victimized by being neglected or excluded?") (Pouwels et al., 2016). Adolescents could nominate an unlimited number of classmates and also had the option to nominate none of their classmates.

Pouwels et al. (2016) showed that the shortened PRQ is a reliable and valid measure of the bullying participant roles among Dutch adolescents. One item of the assistant scale was removed because Pouwels and colleagues found that it was not a reliable and valid indicator of assistant behavior during adolescence. For all other items, the number of nominations received was counted for each adolescent and standardized within classrooms to control for differences in classroom size. Aggregated mean scores were computed for each scale and again standardized within classrooms into $Z$ scores. Cronbach's $\alpha$ s for the scales were .87 (bully), .69 (assistant), .73 (reinforcer), .84 (defender), .78 (outsider), and .85 (victim).

Based on the criteria of Salmivalli et al. (1996), adolescents were categorized to a participant role when they scored above the classroom mean on the corresponding scale $(Z>0)$. If adolescents met the criterion for more than one role, they were categorized to the role with the highest scale score to ensure that they were categorized to just one role. In line with previous research (e.g., Salmivalli \& Voeten, 2004), adolescents were categorized to one role so that we could directly compare students in different roles and compare our findings with other studies. Adolescents who scored below average on all scales were not categorized into any role.

The assistant and reinforcer scales were highly correlated $(r=.61)$. In addition, for $15 \%$ of the participants, their scores on the assistant and reinforcer scales differed by less than .1, indicating that they scored equally high on both roles. These results indicated that adolescents do not always make a clear distinction between the assistant and reinforcer roles. In addition, in eight classrooms no students or only 1 student was categorized in the assistant or reinforcer role. Distinguishing assistants from reinforcers in these classrooms would result in missing data for adolescents' evaluations of actual peers. Therefore, like other Dutch studies (e.g., Goossens, Olthof, \& Dekker, 2006), we combined assistants and reinforcers into one follower group.

\section{Evaluations of the general concept of bullying}

Evaluations of the general concept of bullying were assessed with the attitude toward bullying scale (Salmivalli \& Voeten, 2004; Scholte et al., 2010). Adolescents rated how much they agreed with 10 statements about bullying (e.g., "Bullying may be fun sometimes," "It is not that bad if you laugh with others when someone is being bullied") on a 5-point scale ( $1=$ strongly disagree, $5=$ strongly agree). After recoding and averaging the items, a higher scale score indicated a more positive attitude toward bullying. Cronbach's $\alpha$ was .77. 
Table 2

Demographics of sample Phase 1 and subsample Phase 2 .

\begin{tabular}{lll}
\hline & Sample Phase 1 $(N=1477)$ & Subsample Phase 2 $(N=163)$ \\
\hline Girls (\%) & 48.3 & 57.7 \\
Mean age (SD) (years) & $16.38(0.80)$ & $16.34(0.79)$ \\
School level (\%) & & \\
Prevocational track education (VMBO) & 18.6 & 11.7 \\
Intermediate secondary education (HAVO) & 36.8 & 31.9 \\
College preparatory education (VWO) & 44.7 & 56.4 \\
Ethnicity (\%) & & \\
Caucasian & 81.4 & 81.6 \\
Moroccan & 1.6 & 1.2 \\
Turkish & 1.7 & 1.2 \\
Surinamese & 0.9 & 1.8 \\
Antillean/Aruban & 0.9 & 0.6 \\
Other ethnic origin within Europe & 5.8 & 3.7 \\
Other ethnic origin outside Europe & 7.2 & 9.2 \\
Mixed ethnic origin & 0.4 & 0.6 \\
\hline
\end{tabular}

Evaluations of hypothetical peers with different participant roles

To examine adolescents' evaluations of hypothetical peers with a specific participant role, we presented adolescents with a movie including two video clips with six cartoon characters, each one representing a participant role. The fragments were partly based on the game of the KiVa anti-bullying program (Kärnä et al., 2011). Girls saw a movie with female cartoon characters; boys saw a movie with male cartoon characters. The movies were created with the online GoAnimate movie maker. A description of the video clips can be found in 'Appendix: Description of video clips'.

We selected the cartoon characters from a pool of 15 male and 15 female characters. A pilot study was conducted to select the most average-looking characters from the pool. Each cartoon character was rated by 46 adolescents ( $20 \%$ boys, $M_{\text {age }}=17.67$ years, $S D=1.07$ ) on how likeable, popular, aggressive, and attractive each character came across. We selected the six male and six female cartoon characters who were rated most average on these measures. We randomly assigned the characters to the participant roles. An overview of the appearance of the cartoon characters can be found in Figs. B1 and B2 of 'Appendix: Target stimuli and evaluative stimuli'.

Adolescents were instructed to watch the first video clip. After the clip, the participant roles of bullying were explained by linking the participant roles to the cartoon characters. We also gave a description of the characteristics of each participant role, supported by snapshots from the video clip. After adolescents read the instruction, they were asked to watch the video again and to pay attention to the participant roles of the cartoon characters. Subsequently, the second clip was shown. This clip included the same characters with the same participant roles in a different situation. After the second clip, a manipulation check was conducted. Adolescents were asked to link the cartoon characters to the bullying roles to ensure that they correctly associated the characters with the roles. When adolescents did not fill out the manipulation check correctly, the second fragment was shown again, followed by an additional manipulation check.

Explicit evaluations of hypothetical peers with different participant roles. To determine adolescents' explicit evaluations of hypothetical peers in each participant role, adolescents rated each cartoon character on the item: "How much do you like someone like this cartoon character?" on a 7-point Likert scale $(1=$ not at all, 7 = very much $)$.

Implicit evaluations of hypothetical peers with different participant roles. Adolescents completed six movie-primed ST-IATs, one for each participant role. The design of the tasks was based on the brief ST-IAT (Bluemke \& Friese, 2008). Instead of words, we used pictures of the bullying role cartoon characters as target stimuli and of positive and negative objects (see 'Appendix: Target stimuli and evaluative stimuli') as evaluative stimuli. Participants were told that they were going to complete a 
reaction time task. They were asked to categorize pictures as quickly as possible without making errors. To enhance their motivation, adolescents could win a voucher of 10 euros if they were the fastest participant with the fewest errors.

The task was programmed in Inquisit 4.0. A Java applet presented the stimuli to adolescents and recorded their responses and response latencies in milliseconds. After participants completed the task, the applet sent the data back to the Web server. An overview of the structure of the ST-IAT is provided in Table 3. Adolescents started with a practice block in which they needed to categorize the positive and negative pictures by pushing the "a" and "l" buttons on the left and right of the keyboard, respectively. In the next block, in addition to positive and negative pictures, pictures of the cartoon character with a specific bullying participant role were shown. In this first block, both the positive and cartoon character pictures needed to be categorized with the left response button. Negative pictures had to be categorized with the right response button. In the second block, the response buttons for the positive and negative pictures remained the same, but the pairing of the cartoon character changed. Both the negative pictures and the cartoon character pictures were now categorized with the right response button. Thus, for each participant role, two combined blocks were presented (participant role + positive stimuli and participant role + negative stimuli). Before each block, a written instruction was presented. As a reminder, category labels were listed at the top of the screen during the task. When an error was made, a red cross appeared on the screen. Each block consisted of 35 trials except for the practice block (20 trials). The interstimulus interval was $250 \mathrm{~ms}$. Blocks and trials were presented in a random order out of 12 block order versions. Both the order of combined blocks (i.e., roles) and the combination of target stimuli and evaluative stimuli (positive + target vs. negative + target) in each initial block were counterbalanced across block order versions. Stimuli were presented in a random order within blocks. Shorter response latencies in the participant role and positive stimuli block than in the participant role and negative stimuli block were assumed to indicate stronger positive associations than negative associations with that role (Bluemke \& Friese, 2008).

We prepared the latencies in line with the procedure of Bluemke and Friese (2008). Data analysis was based on correct trials; we omitted the latencies of incorrect trials. Reaction times that were too fast ( $<300 \mathrm{~ms}$ ) or too slow ( $>3000 \mathrm{~ms}$ ) were replaced by these cutoff values ( 300 or $3000 \mathrm{~ms}$ ). Latencies were standardized to $Z$ scores within individuals across all blocks with the exception of the practice blocks. In this way, we controlled for interindividual differences in adolescents' response latencies and latency variability. Latencies from the first 3 trials of each block were removed because adolescents' reaction times in these trials were considerably higher on average than in the other trials $(Z>1)$. The data from 5 adolescents who made errors in more than $20 \%$ of the trials within one combined block were removed. Subsequently, average latency scores were calculated for each block.

The ST-IAT effects were calculated by subtracting the average latency score of the participant role + positive stimuli block from the average latency score of the participant role + negative stimuli block.

Table 3

Structure of the single-target implicit association task.

\begin{tabular}{|c|c|c|c|c|c|c|}
\hline \multirow[t]{2}{*}{ Block } & \multirow[t]{2}{*}{ Task description } & \multirow[t]{2}{*}{ Left key concepts } & \multirow[t]{2}{*}{ Right key concepts } & \multicolumn{3}{|c|}{ Number of stimuli } \\
\hline & & & & Positive & Negative & Role \\
\hline 1 & Practice block & Positive & Negative & 10 & 10 & - \\
\hline 2 & Initial block & Positive + bully & Negative & 10 & 15 & 10 \\
\hline 3 & Reversed block & Positive & Negative + bully & 15 & 10 & 10 \\
\hline 4 & Initial block & Positive + assistant & Negative & 10 & 15 & 10 \\
\hline 5 & Reversed block & Positive & Negative + assistant & 15 & 10 & 10 \\
\hline 6 & Initial block & Positive + reinforcer & Negative & 10 & 15 & 10 \\
\hline 7 & Reversed block & Positive & Negative + reinforcer & 15 & 10 & 10 \\
\hline 8 & Initial block & Positive + defender & Negative & 10 & 15 & 10 \\
\hline 9 & Reversed block & Positive & Negative + defender & 15 & 10 & 10 \\
\hline 10 & Initial block & Positive + outsider & Negative & 10 & 15 & 10 \\
\hline 11 & Reversed block & Positive & Negative + outsider & 15 & 10 & 10 \\
\hline 12 & Initial block & Positive + victim & Negative & 10 & 15 & 10 \\
\hline 13 & Reversed block & Positive & Negative + victim & 15 & 10 & 10 \\
\hline
\end{tabular}


Table 4

Correlations among evaluations of the general concept of bullying, explicit evaluations of hypothetical and actual peers, and implicit evaluations of hypothetical peers ( $N=163$ ).

\begin{tabular}{|c|c|c|c|c|c|c|c|c|c|c|c|c|c|c|c|c|}
\hline \multicolumn{2}{|c|}{$\begin{array}{l}\text { General concept of } \\
\text { bullying }\end{array}$} & \multicolumn{5}{|c|}{ Explicit hypothetical peers } & \multicolumn{5}{|c|}{ Explicit actual peers } & \multicolumn{5}{|c|}{ Implicit hypothetical peers } \\
\hline & 1 & 2 & 3 & 4 & 5 & 6 & 7 & 8 & 9 & 10 & 11 & 12 & 13 & 14 & 15 & 16 \\
\hline \multicolumn{17}{|c|}{ Explicit hypothetical peers } \\
\hline 2. Bully & $.37^{* * * *}$ & & & & & & & & & & & & & & & \\
\hline 3. Follower & $.30^{* * *}$ & $.59^{* * * *}$ & & & & & & & & & & & & & & \\
\hline 4. Defender & $-.41^{* * * *}$ & $-.55^{* * * *}$ & $-.46^{* * *}$ & & & & & & & & & & & & & \\
\hline 5. Outsider & .14 & -.07 & -.01 & .07 & & & & & & & & & & & & \\
\hline 6. Victim & $-.38^{* * *}$ & $-.47^{* * * *}$ & $-.24^{* *}$ & $.54^{* * *}$ & .06 & & & & & & & & & & & \\
\hline \multicolumn{17}{|c|}{ Explicit actual peers } \\
\hline 7. Bully & .06 & .15 & .07 & .01 & -.03 & -.02 & & & & & & & & & & \\
\hline 8. Follower & .05 & .10 & .04 & .01 & .04 & -.07 & $.54^{* * *}$ & & & & & & & & & \\
\hline 9. Defender & -.14 & -.01 & -.08 & $.20^{*}$ & .09 & .03 & $.19^{*}$ & $.41^{* * *}$ & & & & & & & & \\
\hline 10. Outsider & -.20 & $-.16^{*}$ & $-.26^{* *}$ & $.31^{* * * *}$ & .13 & .11 & .01 & $.23^{*}$ & $.38^{* * * *}$ & & & & & & & \\
\hline 11. Victim & $-.21^{* * *}$ & -.02 & -.07 & .14 & -.02 & .13 & -.07 & .15 & $.31^{* * *}$ & $.33^{* * *}$ & & & & & & \\
\hline \multicolumn{17}{|c|}{ Implicit hypothetical peers } \\
\hline 12. Bully & .02 & -.05 & -.11 & .02 & .05 & .13 & -.12 & -.11 & -.06 & -.03 & -.04 & & & & & \\
\hline 13. Assistant & -.05 & -.10 & -.11 & .09 & .07 & .08 & .10 & .02 & .01 & -.07 & .05 & .12 & & & & \\
\hline 14. Reinforcer & -.06 & -.03 & .05 & .05 & -.04 & $.20^{*}$ & .05 & .05 & .14 & -.10 & .04 & .01 & .11 & & & \\
\hline 15. Defender & -.02 & -.06 & -.10 & -.07 & .03 & .01 & .00 & -.07 & -.01 & .02 & .00 & .13 & .06 & .11 & & \\
\hline 16. Outsider & -.09 & -.11 & -.14 & .06 & .09 & -.01 & -.07 & -.13 & -.07 & .02 & -.07 & -.01 & .06 & .09 & .12 & \\
\hline 17. Victim & -.10 & $-.23^{* *}$ & -.08 & .02 & .14 & $.19^{*}$ & -.12 & -.11 & -.10 & -.07 & -.07 & .05 & .10 & .11 & -.01 & .11 \\
\hline
\end{tabular}

${ }^{*} \mathrm{p}<.05$.

$p<.01$.

$p<.001$ 
We performed this step for each combined block, resulting in six ST-IAT effects (bully, assistant, reinforcer, defender, outsider, and victim). A positive score implies that an adolescent associated the role faster with positive stimuli than with negative stimuli. This can be interpreted as a positive implicit evaluation of the bullying participant role.

\section{Explicit evaluations of classmates by classmates' participant role}

To determine adolescents' explicit evaluations of peers, adolescents rated how much they liked each classmate on a 6 -point Likert scale $(1=$ not at all, $6=$ very much). We then determined adolescents' explicit evaluations of classmates in each role by computing their mean likeability rating of the classmates in each role. This yielded five scores for each adolescent indicating their explicit evaluations of classmates who were bullies, followers, defenders, outsiders, and victims.

\section{Results}

\section{Preliminary analyses}

Correlations between all study variables are presented in Table 4. Evaluations of the general concept of bullying were positively correlated with their explicit evaluations of hypothetical bullies and followers and were negatively correlated with their explicit evaluations of hypothetical defenders and victims and of actual outsiders and victims. Explicit evaluations of hypothetical and actual defenders were significantly positively correlated. For the other roles, evaluations of hypothetical and actual peers with the same role were not significantly associated. Implicit evaluations were not significantly correlated with most explicit evaluations.

A series of $t$ tests were run to examine gender differences in all study variables. We used a Bonferroni correction to control for multiple testing. Boys viewed the concept of bullying more positively than girls did, $t(125.89)=3.87, p<.001$. Explicitly, boys evaluated actual followers more positively than girls did, $t(161)=3.92, p<.001$. Implicitly, girls evaluated hypothetical victims more positively than boys did, $t(145.01)=-3.21, p=.002$.

\section{Evaluations of bullying}

We ran separate analyses for each type of evaluation: general concept of bullying, explicit evaluation of hypothetical and actual peers, and implicit evaluation of hypothetical peers. In previous studies, girls evaluated bullying more negatively and evaluated supportive behavior toward victims more positively than boys did (Menesini et al., 1997; Rigby, 2005). Unfortunately, it was not possible to test whether gender moderated our expected associations because the numbers of participants in the bully and victim roles were small and the sizes of the "boy bully" ( $n=11)$, "boy victim" $(n=7)$, "girl bully" $(n=4)$, and "girl victim" $(n=14)$ cells were too small for moderation analyses. Therefore, rather than testing moderation, we controlled for gender.

\section{Evaluation of the general concept of bullying}

The overall mean indicated that adolescents had a negative attitude toward bullying $(M=1.76$, $S D=0.54$ ). To examine whether this evaluation differed depending on adolescents' bullying participation role, an analysis of variance (ANOVA; Own Participant Role: bully, follower, defender, outsider, or victim) was run on adolescents' evaluations of the general concept of bullying. Adolescents' own participant role was not significantly related to their evaluation of the general concept of bullying, $F$ $(4,157)=0.90, p=.47, \eta_{\mathrm{p}}^{2}=.02$.

Explicit evaluation of hypothetical versus actual peers with different participant roles

A 5 (Target Participant Role: bully, follower, defender, outsider, or victim) $\times 2$ (Target Type: actual or hypothetical) $\times 5$ (Own Participant Role: bully, follower, defender, outsider, or victim) repeated measures ANOVA was conducted on adolescents' explicit evaluations of hypothetical and actual peers. Target participant role and target type were within-participant factors allowing direct comparisons 
between the target participant roles and between hypothetical and actual targets. The scales for the evaluations of actual and hypothetical peers had the same anchors, but the numbers of scale points varied; actual peers were rated on a 6-point scale, and hypothetical peers were rated on a 7-point scale. The difference was caused by the fact that the actual peer ratings were part of the larger longitudinal study that included other 6-point ratings, and an effort was made to keep all rating scales consistent for the participants. To make the measures comparable, we recoded the ratings of hypothetical peers from a 7-point scale to a 6-point scale. The anchors were rescaled from 1-7 to 1-6, and the intervals between the scale points were rescaled from 1 to $5 / 6$.

In the ANOVA, Mauchley's test indicated that the assumption of sphericity was violated for target role, $\chi^{2}(9)=116.09, p<.001$, and for the interaction between target type and target role, $\chi^{2}(9)$ $=101.49, p<.001$. Therefore, Greenhouse-Geisser corrections of degrees of freedom were used $(\varepsilon=.71)$. Results are presented in Table 5 .

First, we examined whether adolescents differentiated their explicit evaluations by the target peers' participant role and whether these evaluations further depended on the type of target (hypothetical or actual peers). This was the case, as indicated by a significant Target Role $\times$ Target Type interaction, $F(2.86,448.74)=243.12, p<.001, \eta_{\mathrm{p}}^{2}=.61$.

To interpret the interaction, we first examined the multivariate effects of target role for hypothetical and actual peers separately. The multivariate effect for hypothetical peers was significant, $F$ $(4,154)=306.84, p<.001, \eta_{\mathrm{p}}^{2}=.89$. Bonferroni post hoc comparisons showed that adolescents explicitly evaluated a hypothetical defender more positively than all other characters. Adolescents also evaluated the victim character more positively than the outsider, which was evaluated more positively than the follower, which was evaluated more positively than the bully.

The multivariate effect of actual peers (classmates) also was significant, $F(4,154)=39.00, p<.001$, $\eta_{\mathrm{p}}^{2}=.50$. Bonferroni post hoc comparisons showed a different pattern for adolescents' explicit evaluations of actual peers than for those of hypothetical peers. Actual peers who were defenders and outsiders were evaluated more positively than all other roles. Whereas hypothetical followers were evaluated more positively than only bullies, actual followers were evaluated more positively than both bullies and victims. Actual victims were evaluated as negatively as actual bullies.

We also compared adolescents' evaluations of hypothetical and actual peers for each role. These multivariate tests showed that hypothetical bullies, followers, and outsiders were evaluated significantly more negatively than their actual counterparts. In contrast, hypothetical defenders and victims were evaluated significantly more positively than their actual counterparts.

Second, we examined whether adolescents' evaluations of hypothetical and actual peers further depended on their own role. Indeed, there was a significant interaction of target role, target type, and own role, $F(11.43,448.74)=3.02, p=.001, \eta_{\mathrm{p}}^{2}=.07$. To understand the interaction, we first examined the univariate effect of own role on the evaluations of hypothetical peers. There were no significant effects of own role on the explicit evaluations of the hypothetical bully, follower, outsider, and victim characters. There was a significant effect of own role on the explicit evaluations of the hypothetical defender character (see Table 5). Bonferroni post hoc comparisons showed that adolescents who were defenders and outsiders themselves evaluated the defender character more positively than adolescents who were followers did. Adolescents who were bullies and victims did not differ from adolescents in the other roles in their evaluations of the hypothetical defender.

We also examined the univariate effect of own role on the evaluations of classmates (i.e., actual peers) in each role (see Table 5). In contrast to the evaluations of hypothetical peers, adolescents' evaluations of classmates who were bullies, followers, outsiders, and victims did depend on their own role, whereas their evaluations of actual defenders did not. Bonferroni post hoc comparisons revealed that classmates who were bullies or followers were evaluated more positively by adolescents who were followers themselves than by adolescents who were defenders, outsiders, or victims. Adolescents who were bullies did not differ from other adolescents in their evaluations of classmates who were bullies or followers. Whereas there was a significant main effect of own role on the evaluations of actual outsiders, Bonferroni post hoc comparison tests did not show significant differences between adolescents who themselves had different participant roles. Finally, victims were evaluated more positively by adolescents who were followers, defenders, outsiders, and victims themselves than by adolescents who were bullies. 
Table 5

Explicit evaluations of actual and hypothetical peers by classmates' participant role and adolescents' own participant role.

\begin{tabular}{|c|c|c|c|c|c|c|c|c|c|c|c|c|c|c|}
\hline & \multirow{2}{*}{\multicolumn{2}{|c|}{$\begin{array}{l}\text { Total } \\
(N=163) \\
\end{array}$}} & \multicolumn{10}{|c|}{ Own participant role } & \multirow[t]{3}{*}{$F(4,157)$} & \multirow[t]{3}{*}{$\eta_{\mathrm{p}}^{2}$} \\
\hline & & & \multicolumn{2}{|c|}{$\begin{array}{l}\text { Bully } \\
(n=15)\end{array}$} & \multicolumn{2}{|c|}{$\begin{array}{l}\text { Follower } \\
(n=41)\end{array}$} & \multicolumn{2}{|c|}{$\begin{array}{l}\text { Defender } \\
(n=47)\end{array}$} & \multicolumn{2}{|c|}{$\begin{array}{l}\text { Outsider } \\
(n=39)\end{array}$} & \multicolumn{2}{|c|}{$\begin{array}{l}\text { Victim } \\
(n=21)\end{array}$} & & \\
\hline & $M$ & $S D$ & $M$ & $S D$ & $M$ & $S D$ & $M$ & $S D$ & $M$ & $S D$ & $M$ & $S D$ & & \\
\hline \multicolumn{15}{|c|}{ Cartoon character's participant role } \\
\hline Bully & $\underline{1.38}$ & 0.85 & $\underline{1.56}$ & 1.03 & $\underline{1.59}$ & 1.11 & $\underline{1.20}$ & 0.47 & $\underline{1.21}$ & 0.63 & $\underline{1.60}$ & 1.09 & 1.39 & .03 \\
\hline Follower & $\underline{2.08}$ & 0.76 & $\underline{2.44}$ & 0.74 & $\underline{2.10}$ & 0.94 & 1.98 & 0.65 & 2.03 & 0.65 & $\underline{2.13}$ & 0.81 & 0.60 & .02 \\
\hline Defender & $\overline{5.48}$ & 0.79 & $\underline{5.50}_{\underline{a}, \mathrm{~b}}$ & 0.69 & $\overline{5.07}_{\underline{b}}$ & 1.11 & $\overline{5.66} \underline{a}_{a}$ & 0.59 & $\overline{5.76} \underline{a}_{a}$ & 0.43 & $\overline{5.37}_{\underline{a}, \mathrm{~b}}$ & 0.69 & $4.86^{* *}$ & .11 \\
\hline Outsider & 4.07 & 0.88 & $4.33^{\frac{1.10}{2}}$ & 1.14 & 3.93 & 0.84 & 4.03 & 0.70 & 4.18 & 0.95 & 4.06 & 1.00 & 0.95 & .02 \\
\hline Victim & $\underline{4.49}$ & 1.03 & $\underline{4.33}$ & 1.14 & $\underline{4.11}$ & 1.18 & $\underline{4.71}$ & 0.88 & $\underline{4.72}$ & 0.91 & 4.45 & 1.00 & 1.82 & .04 \\
\hline \multicolumn{15}{|c|}{ Classmates' participant role } \\
\hline Bully & 3.57 & 1.33 & $4.12_{\mathrm{a}, \mathrm{b}}$ & 1.34 & $\underline{4.29} \underline{a}_{a}$ & 1.27 & $3.23_{b}$ & 1.35 & $3.31_{b}$ & 1.15 & $3.01_{b}$ & 1.04 & $5.93^{* * * *}$ & .13 \\
\hline Follower & $\underline{4.03}$ & 0.85 & $4.44_{\mathrm{a}, \mathrm{b}}$ & 0.48 & $4.52^{-1}$ & 0.73 & $3.88_{b}$ & 0.92 & $3.81_{\underline{b}}$ & 0.77 & $3.56_{\underline{b}}$ & 0.78 & $6.00^{* * * *}$ & .13 \\
\hline Defender & 4.44 & 0.75 & 4.36 & 0.62 & 4.36 & 0.80 & 4.66 & 0.67 & 4.39 & 0.85 & 4.27 & 0.68 & 1.56 & .04 \\
\hline Outsider & 4.33 & 0.69 & $\overline{4.01}$ & 0.78 & 4.24 & 0.75 & 4.41 & 0.69 & 4.57 & 0.64 & 4.14 & 0.45 & $2.85^{*}$ & .07 \\
\hline Victim & 3.61 & 1.02 & $\underline{2.68} \underline{b}$ & 1.12 & $\underline{3.69} \underline{\underline{a}}$ & 1.07 & $\underline{3.63}$ & 0.97 & $\underline{3.54}$ & 0.78 & $4.24 \mathrm{a}$ & 0.88 & $6.16^{* * *}$ & .14 \\
\hline
\end{tabular}

Note. Means within rows that do not share a subscript were significantly different between adolescents with a different participant role in a Bonferroni post hoc comparison test. Means that are underlined differed significantly between hypothetical peers (cartoon character) and actual peers (classmates) in a Bonferroni post hoc comparison test.

$$
\text { "* } p<.05 \text {. }
$$$$
{ }^{* * * *} p<.001 \text {. }
$$ 
We examined multivariate simple effects to determine whether hypothetical and actual peers in each target role were seen differently by adolescents in each role. Significant differences between hypothetical and actual peers are underlined in Table 5. Hypothetical bullies and followers were evaluated more negatively than actual bullies and followers by adolescents in all roles. Hypothetical defenders were evaluated more positively than actual defenders by all adolescents. Hypothetical outsiders were evaluated more negatively than actual outsiders by adolescents who themselves were defenders or outsiders. Hypothetical victims were evaluated more positively than actual victims by all adolescents except adolescents who themselves were victims.

In summary, although adolescents evaluated both actual and hypothetical defenders more positively than the other roles, hypothetical defenders were evaluated more positively than actual defenders. Hypothetical victims also were evaluated more positively than actual victims. And although actual and hypothetical bullies and followers were evaluated more negatively than the other roles, actual bullies and followers were evaluated more positively than hypothetical bullies and followers. Adolescents' evaluations of actual peers in all roles except defenders depended on their own role, whereas for hypothetical peers only the evaluations of the defender role depended on adolescents' own role.

\section{Implicit evaluation of hypothetical peers with different participant roles}

Adolescents' explicit and implicit evaluations were not directly comparable because they were examined through different tasks with noncomparable metrics. For adolescents' implicit evaluations of hypothetical peers, therefore, we conducted a separate 6 (Target Participant Role: bully, assistant, reinforcer, defender, outsider, or victim) $\times 5$ (Own Participant Role: bully, follower, defender, outsider, or victim) repeated measures ANOVA with target participant role as a repeated measures factor. The correlation between implicit evaluations of the assistant and reinforcer cartoon character was low. Therefore, we separated implicit evaluations of the assistant and reinforcer target in the analysis, in contrast to the analysis regarding adolescents' explicit evaluations.

There was a significant effect of target participant role, $F(5,785)=4.96, p<.001, \eta_{\mathrm{p}}^{2}=.03$. Adolescents implicitly evaluated the defender cartoon character significantly more positively than the assistant, reinforcer, and victim characters (see Table 6).

Finally, we examined whether adolescents' implicit evaluations of hypothetical peers with different participant roles varied by their own participant role. There was no significant interaction between cartoon character role and own role for implicit evaluations.

In summary, adolescents evaluated the defender role most positively both explicitly and implicitly. Adolescents made differences between the other roles only in their explicit evaluations, not in the implicit evaluations. In addition, unlike their explicit evaluations, adolescents' implicit evaluations of hypothetical peers did not depend on their own role.

\section{Discussion}

To gain more insight into the association between bullying involvement and bullying evaluations, this study extended previous research beyond evaluations of the general concept of bullying and

\section{Table 6}

Implicit evaluations of participant role cartoon characters by adolescents' own participant role.

\begin{tabular}{|c|c|c|c|c|c|c|c|c|c|c|c|c|c|c|}
\hline & \multirow{2}{*}{\multicolumn{2}{|c|}{$\begin{array}{l}\text { Total } \\
(N=163) \\
\end{array}$}} & \multicolumn{10}{|c|}{ Own participant role } & \multirow[t]{3}{*}{$F(4,157)$} & \multirow[t]{3}{*}{$\eta_{\mathrm{p}}^{2}$} \\
\hline & & & \multicolumn{2}{|c|}{$\begin{array}{l}\text { Bully } \\
(n=15) \\
\end{array}$} & \multicolumn{2}{|c|}{$\begin{array}{l}\text { Follower } \\
(n=41)\end{array}$} & \multicolumn{2}{|c|}{$\begin{array}{l}\text { Defender } \\
(n=47)\end{array}$} & \multicolumn{2}{|c|}{$\begin{array}{l}\text { Outsider } \\
(n=39)\end{array}$} & \multicolumn{2}{|c|}{$\begin{array}{l}\text { Victim } \\
(n=21)\end{array}$} & & \\
\hline & $M$ & $S D$ & $M$ & $S D$ & $M$ & $S D$ & $M$ & $S D$ & $M$ & $S D$ & $M$ & $S D$ & & \\
\hline \multicolumn{15}{|c|}{ Cartoon character's participant role } \\
\hline Bully & .03 & .38 & -.04 & .54 & -.02 & .36 & .02 & .31 & .07 & .39 & .09 & .44 & 0.44 & .01 \\
\hline Assistant & .00 & .35 & -.13 & .50 & .07 & .31 & -.01 & .35 & .01 & .30 & .00 & .36 & 0.94 & .02 \\
\hline Reinforcer & .00 & .34 & -.15 & .25 & -.01 & .35 & .07 & .41 & .02 & .30 & -.04 & .29 & 0.91 & .02 \\
\hline Defender & .14 & .35 & .05 & .34 & .14 & .37 & .16 & .36 & .14 & .36 & .19 & .23 & 0.33 & .01 \\
\hline Outsider & .08 & .35 & .13 & .43 & -.03 & .39 & .08 & .32 & .12 & .33 & .17 & .34 & 1.28 & .03 \\
\hline Victim & .01 & .35 & -.12 & .31 & -.02 & .37 & .03 & .32 & .02 & .37 & .07 & .38 & 0.28 & .01 \\
\hline
\end{tabular}


hypothetical bullying situations. We examined adolescents' evaluations of bullying at three levels of specificity: the general concept of bullying, hypothetical peers with a specific participant role, and actual peers with a specific participant role. For hypothetical peers, we examined both explicit and implicit evaluations. For each level of specificity, we also examined whether adolescents' evaluations of bullying varied by their own participant role.

\section{Adolescents' evaluations of the general concept of bullying}

We first examined adolescents' evaluations of the general concept of bullying. Based on Salmivalli and Voeten's (2004) study, we expected that the general concept of bullying would be evaluated more positively by bullies and their followers than by others. However, adolescents' evaluations of bullying did not depend on their own role; all adolescents evaluated the general concept of bullying equally negatively. Could this be an example of moral hypocrisy? People often do not practice what they preach (Stone \& Fernandez, 2008). In this study, bullies and followers endorsed the moral standard that bullying is bad but denied this view in their own behavior. Alternatively, socially desirable answering may be at play (Scholte et al., 2010). The fact that adolescents evaluated bullying negatively is in line with previous research (Boulton et al., 2012; Menesini et al., 1997; Scholte et al., 2010) and fits with Scholte et al. (2010) assumption that adolescents' bullying attitudes become more approving until early adolescence but then become less positive again when adolescents get older.

\section{Evaluations of hypothetical versus actual peers with different bullying participant roles}

Second, we examined adolescents' evaluations of hypothetical peers with different participant roles. Based on Gini, Pozzoli, et al. (2008), we expected that adolescents would evaluate hypothetical peers in pro-bullying roles relatively negatively and would evaluate hypothetical peers in the defender role relatively positively. This was confirmed; the more engaged hypothetical peers were in bullying behavior, the more negatively they were evaluated. A hypothetical peer who tried to stop bullying (a defender) was evaluated most positively. Adolescents' explicit evaluations of hypothetical peers in the participant roles were in line with their evaluations of the general concept of bullying.

We also examined adolescents' evaluations of actual peers in each participant role. As expected, adolescents liked classmates in defender and outsider roles more than classmates in bully, follower, and victim roles. Moreover, adolescents' explicit evaluations of the participant roles differed between hypothetical and actual peers. In terms of absolute scores, hypothetical bullies and followers clearly were least liked by all adolescents, but actual bullies and followers were not as strongly disliked as the other roles. The difference may be explained by different associations with hypothetical versus actual bullies. In the movie clips, the emphasis was on the negative characteristics of bullies such as their aggression. In real life, bullying is also related to positively valued status and behavioral characteristics. For example, adolescent bullies and followers score high on peer-valued characteristics and popularity (Pouwels et al., 2016; Vaillancourt, Hymel, \& McDougall, 2003). Although adolescents may disapprove of bullies' aggression, they may value some of their other characteristics, such as good looks, athleticism, status, and leadership skills, which may compensate for their aggression (Pouwels et al., 2016; Vaillancourt et al., 2003).

There was also a difference in the evaluations of victims, with hypothetical victims being liked more than actual victims. Specifically, hypothetical victims were liked less than defenders but more than outsiders, bullies, and followers. In contrast, actual victims were as disliked as bullies in their classroom. Although adolescents may disapprove of bullying and feel sorry for victims in general, they seem to tolerate or even approve of the bullying of certain victims. They might blame victims and believe that they deserve their plight because of their personalities or behavior (Hara, 2002). This idea is supported by studies showing that adolescents tend to hold victimized classmates personally responsible for their situations (Schuster, 2001; Teräsahjo \& Salmivalli, 2003). Alternatively, it may be adaptive for adolescents to separate themselves from victimized classmates. Dissociation from victims might reduce their own risk of moving down the status hierarchy (Juvonen \& Galván, 2008). That fear is not unrealistic; victimization leads to increased rejection over time (Hodges \& Perry, 1999). 
Although all adolescents evaluated the general concept of bullying negatively, their evaluations of hypothetical and actual others in different roles depended on their own role. Followers evaluated a defender cartoon character less positively than defenders and outsiders did, whereas bullies did not differ from any other role. Because defenders hinder bullying, one could expect that both bullies and followers would evaluate defending behavior less positively than other adolescents would. The fact that this pattern was found only for followers, but not for bullies, may be due to socially desirable answering by bullies. Another explanation is that bullies sometimes defend each other and, thus, may sometimes also benefit from defending behavior (Huitsing, Snijders, van Duijn, \& Veenstra, 2014). The evaluations of the other cartoon characters did not depend on adolescents' own role.

The evaluations of actual peers in different participant roles also depended on adolescents' own role. Classmates who were bullies or followers were evaluated more positively by adolescents who were followers themselves than by adolescents who were defenders, outsiders, and victims. Peers tend to affiliate with classmates who behave the same way as themselves in bullying situations (Huitsing \& Veenstra, 2012; Salmivalli, Huttunen, \& Lagerspetz, 1997) and, therefore, may like them more (Byrne, 1971). Classmates in a victim role were evaluated more negatively by bullies than by adolescents in other roles (including followers). Together, these findings suggest that followers may participate in bullying because they are affiliated with or want to affiliate with bullies (Olthof \& Goossens, 2008), whereas bullies may strategically use aggression on victims they dislike.

\section{Implicit evaluations of hypothetical peers with different bullying participant roles}

At the implicit level, adolescents evaluated the defender role more positively than the victim, assistant, and reinforcer roles. In contrast to our hypothesis, adolescents made no further distinction in the evaluations of the other roles. Moreover, contrary to adolescents' explicit evaluations, their implicit evaluations of the roles were not affected by their own role. This indicates that, overall, all adolescents implicitly evaluated the defender role positively. This may be explained by the fact that youths are taught that it is good to help others in trouble. Adolescents who have heard this message many times may have formed automatic positive associations with defending. The positive implicit association with defending might not be formed only through teaching. Children are already born with a sense of moral goodness-a tendency to feel empathic concern for others and to help them despite potential personal costs (Hamlin, 2013). In line with this, there is some evidence that moral judgment can be the result of multiple systems. In addition to cognitive systems that enable conscious reflection, intuitive affective systems also play a role in moral reasoning (Cushman, Young, \& Hauser, 2006; Greene, Nystrom, Engell, Darley, \& Cohen, 2004). Consequently, one would expect adolescents to have negative implicit associations with bullies. Because adolescents' implicit evaluations of bullies did not differ from their evaluations of the other roles, more research on this association is needed.

Implicit evaluations are likely to influence automatic behavior (Fazio, 1990; Gawronski \& Bodenhausen, 2006). This theory is supported by research on prejudice that shows that people's implicit attitudes toward minority groups predict unfriendly behavior toward and keeping a distance from minorities (Dotsch \& Wigboldus, 2008; McConnell \& Leibold, 2001). Moreover, implicit interpersonal evaluations are related to friendly behavior in a group discussion task and to behavior in an online ball-tossing game, beyond explicit evaluations (Krause, Back, Egloff, \& Schmukle, 2014). More research is needed on how adolescents' peer evaluations are related to their social interaction with these peers. Adolescents' automatic initial response to bullying is likely driven by their implicit evaluations of defending when they do not have much opportunity to think their response through. However, only some adolescents seem to behave in accordance with their implicit evaluations and actually intervene in bullying (Salmivalli, 2010). When adolescents have more time or opportunity to think about their response, they may choose to act on other more explicit attitudes and considerations (Olson \& Fazio, 2009). They could, for example, refrain from defending because of its anticipated costs-to become the next target of bullying (Pöyhönen, Juvonen, \& Salmivalli, 2010). 
Limitations and suggestions for further research and practice

This study has some limitations. First, we only controlled for gender in the analyses and were not able to test whether the effects were different for boys and girls due to the limited sample size in Phase 2. Previous research has shown that girls evaluate pro-bullying behavior more negatively than boys do (Boulton et al., 2012; Menesini et al., 1997). Future studies on adolescents' evaluations of the bullying participant roles should further examine gender differences.

Second, hypothetical and actual peers were contextualized in a different way before they were evaluated. Cartoon characters were evaluated after they behaved in line with their role in a bullying scenario. In contrast, actual peers were evaluated without reference to their behavior in bullying situations. We do not know to what degree the differences between actual and hypothetical peers were due to the contextualization of their behavior rather than their real-life status. A suggestion for further research is to examine how adolescents evaluate actual peers when they are asked to consider how their real-life peers behave in bullying situations.

Third, the roles of actual peers were derived from nominations aggregated across all peers. Not all adolescents who evaluated a peer in a certain role actually nominated that peer for that particular role. For example, we did not examine at the dyadic level whether adolescents who evaluated actual bullies relatively positively also personally named them as bullies. Further research could address this issue by taking dyadic nominations into account.

Beyond these limitations, several suggestions can be made for further research. Just as at the explicit level, there may be a discrepancy between the evaluations of hypothetical and actual peers at the implicit level. Examining implicit evaluations of actual peers was beyond the scope of this study because the paradigm is very time-consuming. Implicit evaluations of classmates with specific roles may be examined in future studies by means of an approach avoidance task (Lansu et al., 2013). Names or pictures of classmates could then be the target stimuli. By matching the participant roles with the implicit evaluative responses of the peers, implicit evaluations of classmates in each participant role could be examined.

In this study, classroom attitudes and normative beliefs of bullying were not examined because a subsample from each classroom participated in Phase 2. During adolescence, classroom norms of bullying predicted adolescents' individual bullying, reinforcer, and defender behavior after controlling for individual attitudes (Salmivalli \& Voeten, 2004; Scholte et al., 2010). Additional studies of adolescents' evaluations of the participant roles of bullying at the individual level, as well as at the classroom level, are needed. Such studies could further extend our knowledge of the evaluations of bullying participant roles at different levels.

Students could be categorized to just one role based on the criterion we used, with the advantage that we could directly compare how these roles differed from each other. However, in real life, some youths are involved in multiple roles (Goossens et al., 2006). We did not take adolescents' secondary role into account because of the relatively small number of students in each role. Future research needs to examine the evaluations of bullying among adolescents with multiple roles. Another related limitation is that assistants and reinforcers were combined into one group to increase its sample size, a procedure that has been used before (e.g., Goossens et al., 2006). Although these scales were highly correlated, there may have been some differences between these two roles that we were not yet able to examine.

The findings of this study may help us to understand why adolescents do not always behave according their general bullying attitudes. Adolescents' evaluations of the bullying roles depended on whether they evaluated hypothetical or actual peers. This raises the possibility that studies on adolescents' bullying evaluations by means of general concepts or hypothetical vignettes cannot be translated to real-life interactions with peers. The current study has raised important questions about the ecological validity of general self-reported measures of attitudes and hypothetical vignettes. Hypothetical paradigms have been used in a wide range of developmental studies, for example, to examine hostile attributions of intent in ambiguous situations, emotional responses to interactions, and intended behavioral reactions to social situations (see, e.g., Crick \& Dodge, 1996; Graham \& Hoehn, 1995). A next step is to develop paradigms that involve actual peers. 
The current findings might contribute to the refinement of anti-bullying programs. Many antibullying programs aim to change adolescents' attitudes toward bullying in such a way that adolescents become more disapproving of bullying (Olweus, 1994; Salmivalli, Kaukiainen, \& Voeten, 2005; Smith \& Ananiadou, 2003; Ttofi \& Farrington, 2011). However, this study demonstrates that adolescents already have a relatively negative attitude toward bullying behavior. Moreover, all adolescents, regardless of their own role, had relatively positive explicit and implicit associations with defending behavior. Already at an automatic level, youths see defending as positive. Anti-bullying programs do not need to convince youths that defending is the right thing to do. Instead, they may rather focus on the factors that are needed to effectively defend victims such as empathy and a sense of self-efficacy (Gini, Albiero, Benelli, \& Altoe, 2008; Pöyhönen et al., 2010).

It may also be helpful to show adolescents the discrepancy in their evaluations of hypothetical and actual peers; they seem to evaluate hypothetical peers who are victimized less negatively than actual peers who are victimized. From a cognitive dissonance perspective, this discrepancy may be the result of inconsistent beliefs (Gawronski, 2012). Youths may disapprove of bullying, on the one hand, but may have a positive impression of bullies, on the other. There are different ways to resolve cognitive dissonance. Youths' motivation to believe in the truth of their desired beliefs may affect how they resolve this inconsistency (Gawronski, 2012). When youths are strongly motivated to maintain a positive impression of bullies, they may resolve the inconsistency by justifying bullies' behavior by holding their classmate victims responsible for being bullied (Hara, 2002; Hymel, Schonert-Reichl, Bonanno, Vaillancourt, \& Rocke Henderson, 2010). As a result, they may evaluate actual victims more negatively than hypothetical victims.

This is not the only way to resolve the inconsistency; adolescents may also question their positive impression of bullies. To motivate adolescents in this way, they could be encouraged to reflect on the difference in their evaluations of actual and hypothetical bullies. As a result, they may become more motivated to solve the inconsistency by negatively evaluating all bullying incidents (Fox, Elder, Gater, \& Johnson, 2010). Many interventions aim to enhance youths' empathic skills (Ttofi \& Farrington, 2011), which may help them to understand and experience what their victimized classmates feel (van Noorden, Haselager, Cillessen, \& Bukowski, 2015). This may lead to more favorable evaluations of actual victims and more negative evaluations of actual bullies that may reduce pro-bullying behavior and increase defending.

\section{Conclusion}

This study shows that adolescents, regardless of their own participant role, evaluate the general concept of bullying negatively. Both explicitly and implicitly, hypothetical peers with a defender role were evaluated most positively. Adolescents' own role affected their explicit evaluations of actual and hypothetical peers, but not their implicit evaluations of hypothetical peers. These results imply that future research on bullying attitudes must take adolescents' own participant role into account. When adolescents evaluated hypothetical peers, bullies were evaluated negatively by all classmates and victims were evaluated more positively than the other roles. However, when adolescents evaluated their own classmates, the differences between bullies and followers and the other roles were smaller and victims were evaluated as negatively as bullies. Therefore, further research should take into account that adolescents' evaluations of actual peers differ from their evaluations of hypothetical peers.

\section{Acknowledgments}

This research was supported by Research Talent Grant 406-12-110 from the Netherlands Organisation for Scientific Research awarded to J. Loes Pouwels. The authors are grateful to the adolescents, parents, teachers, and school administrators who made this research possible. We also thank the research assistants who assisted with the data collection. We thank Anniek te Dorsthorst and Ilse Luteijn for their assistance during Phase 2 of the study. 


\section{Appendix: Description of video clips}

Two video clips were presented. Text balloons were used to clarify the communication between the characters. Clips with male characters were shown to boys; clips with female characters were presented to girls. A description of the male version of the clips is given below.

The first video clip was a bullying situation in which the victim entered the school canteen and ordered a drink. He then sat down with two peers, the bully and the assistant, after which the bully took the initiative to sit somewhere else because he did not want to sit with peers who are "not sociable." The assistant walked with the bully. When the bully and assistant had joined two other peers in the school canteen, they started to miscall the victim and to point at him. The reinforcer encouraged the bully by laughing. The victim looked unhappy but did not do anything. After a while, the defender intervened by getting angry with his peers. He walked to the victim and tried to comfort him. The outsider was present in the school canteen but stayed out of the situation.

The second video clip was situated in the hallway at school. At the beginning of the clip, the victim entered the hallway and walked to his locker. Next to his locker, the bully and assistant talked to each other. The victim got a book out of his locker. Then, the bully and assistant noticed the victim and the bully compelled the victim to give the book to him. When he got the book in his hands, the bully started ridiculing the victim for reading such a book. The assistant joined the bully. The reinforcer started laughing at and pointing at the victim. The bully threw the book on the ground and stepped on the book. The victim started crying. Then, the defender intervened in the situation and threatened to call the teacher. The bully decided to leave the locker area, and the assistant walked away together with the bully. The defender tried to comfort the victim. The outsider was present in the hallway but stayed out of the situation.

\section{Appendix: Target stimuli and evaluative stimuli}

See Figs. B1-B4.
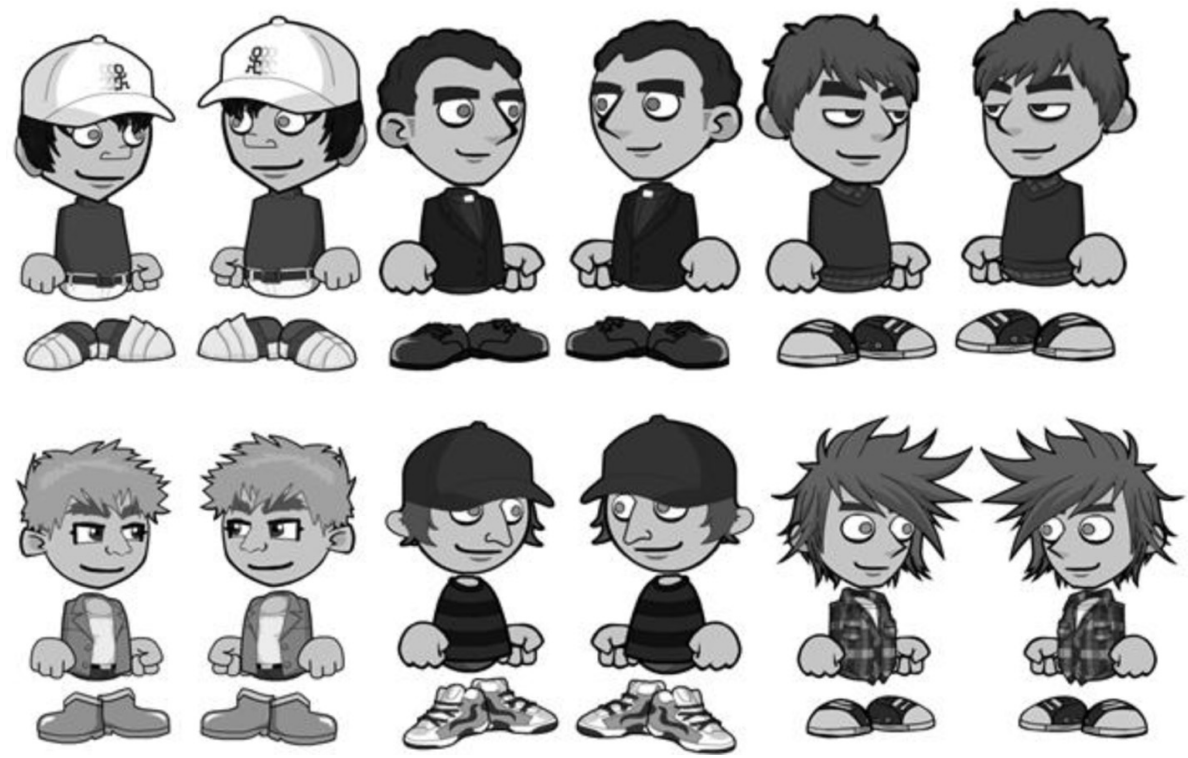

Fig. B1. Target stimuli for boys. Note. All stimuli were presented in color in the single-target implicit association task (ST-IAT). 


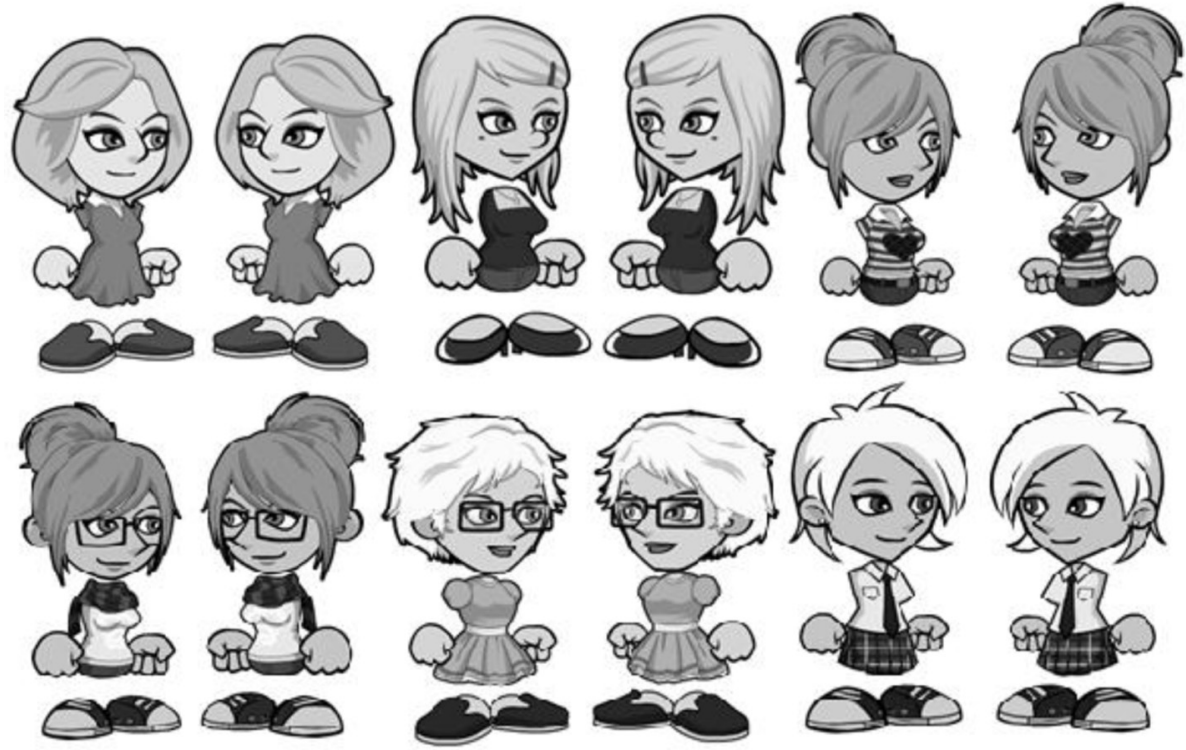

Fig. B2. Target stimuli for girls. Note. All stimuli were presented in color in the single-target implicit association task (ST-IAT).
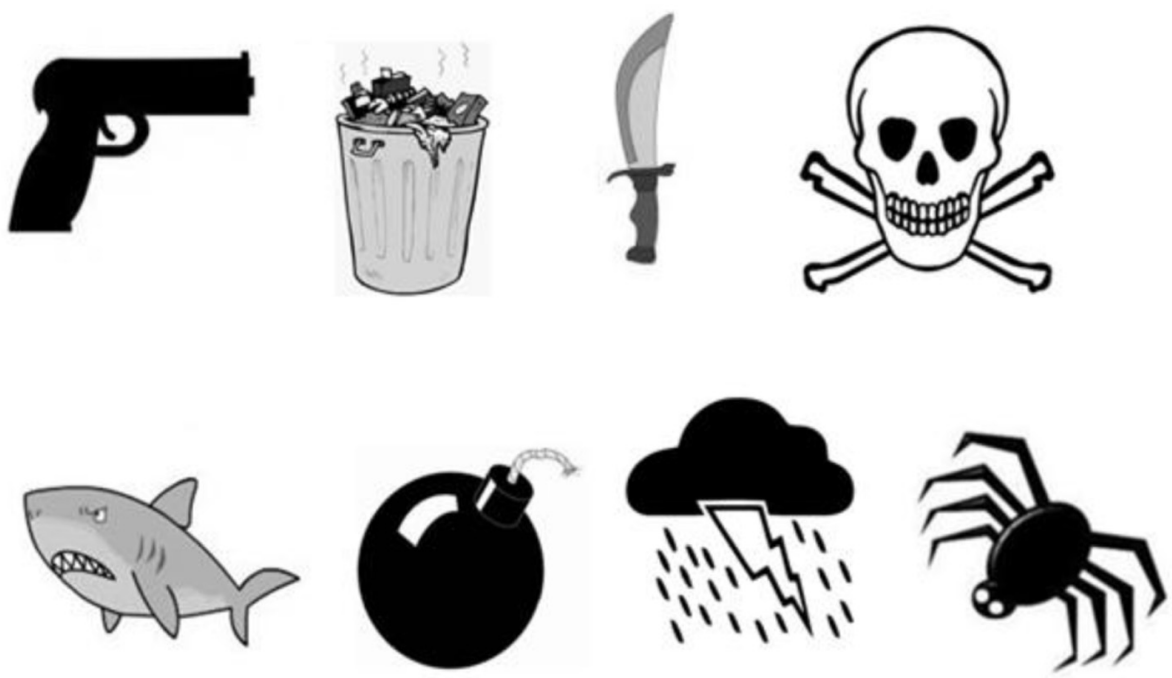

Fig. B3. Negative evaluative stimuli. Note. All stimuli were presented in color in the single-target implicit association task (STIAT). 

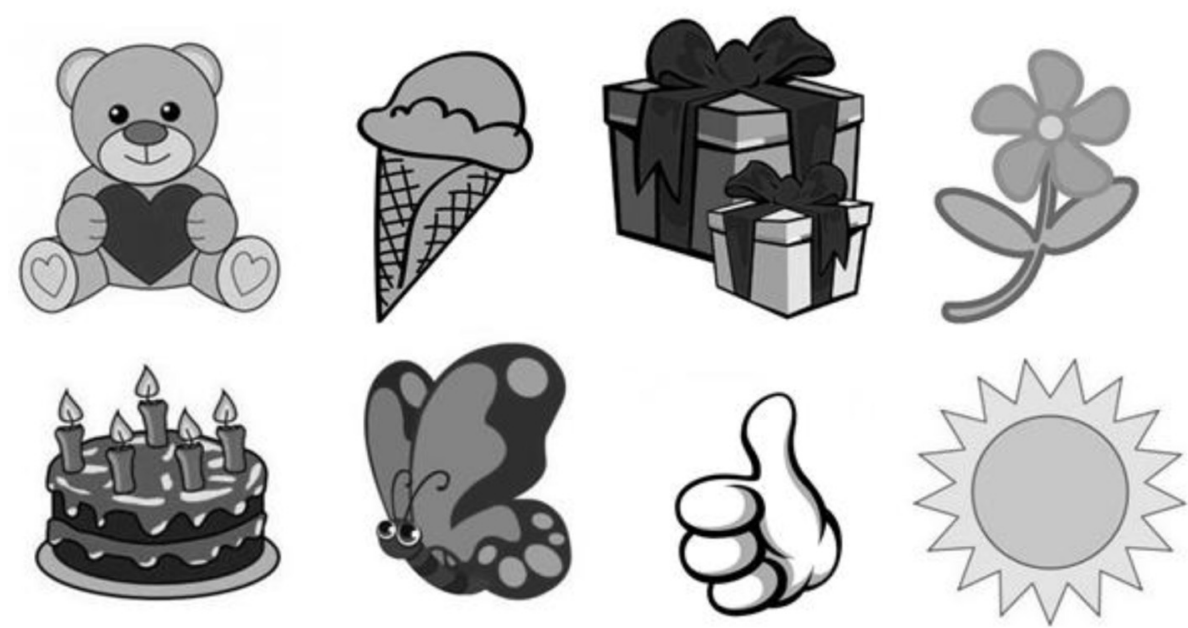

Fig. B4. Positive evaluative stimuli. Note. All stimuli were presented in color in the single-target implicit association task (STIAT).

\section{References}

Almeida, A., Correia, I., \& Marinho, S. (2010). Moral disengagement, normative beliefs of peer group, and attitudes regarding roles in bullying. Journal of School Violence, 9, 23-36.

Andreou, E., Vlachou, A., \& Didaskalou, E. (2005). The roles of self-efficacy, peer interactions, and attitudes in bully-victim incidents: Implications for intervention policy-practices. School Psychology International, 26, 545-562.

Bluemke, M., \& Friese, M. (2008). Reliability and validity of the single-target IAT (ST-IAT): Assessing automatic affect towards multiple attitude objects. European Journal of Social Psychology, 38, 977-997.

Boulton, M., Lloyd, J., Down, J., \& Marx, H. (2012). Predicting undergraduates' self-reported engagement in traditional and cyberbullying from attitudes. Cyberpsychology, Behavior, and Social Networking, 15, 141-147.

Boulton, M. J., Trueman, M., \& Flemington, I. (2002). Associations between secondary school pupils' definitions of bullying, attitudes towards bullying, and tendencies to engage in bullying: Age and sex differences. Educational Studies, 28, 353-370.

Byrne, D. (1971). The attraction paradigm. New York: Academic Press.

Cillessen, A. H. N., \& Rose, A. J. (2005). Understanding popularity in the peer system. Current Directions in Psychological Science, $14,102-105$.

Crick, N. R., \& Dodge, K. A. (1996). Social information-processing mechanisms in reactive and proactive aggression. Child Development, 67, 993-1002.

Cushman, F., Young, L., \& Hauser, M. (2006). The role of conscious reasoning and intuition in moral judgment: Testing three principles of harm. Psychological Science, 17, 1082-1089.

De Houwer, J. (2006). What are implicit measures and why are we using them? In R. W. Wiers \& A. W. Stacy (Eds.), Handbook of implicit cognition and addiction (pp. 11-28). Thousand Oaks, CA: Sage.

Dijksterhuis, A., \& Aarts, H. (2003). On wildebeests and humans: The preferential detection of negative stimuli. Psychological Science, $14,14-18$.

Dotsch, R., \& Wigboldus, D. H. J. (2008). Virtual prejudice. Journal of Experimental Social Psychology, 44, 1194-1198.

Fazio, R. H. (1990). Multiple processes by which attitudes guide behavior: The MODE model as an integrative framework. In P. Z. Mark (Ed.). Advances in experimental social psychology (Vol. 23, pp. 75-109). San Diego: Academic Press.

Fox, C. L., Elder, T., Gater, J., \& Johnson, E. (2010). The association between adolescents' beliefs in a just world and their attitudes to victims of bullying. British Journal of Educational Psychology, 80, 183-198.

Gawronski, B. (2012). Back to the future of dissonance theory: Cognitive consistency as a core motive. Social Cognition, 30, $652-668$.

Gawronski, B., \& Bodenhausen, G. V. (2006). Associative and propositional processes in evaluation: An integrative review of implicit and explicit attitude change. Psychological Bulletin, 132, 692-731.

Gini, G., Albiero, P., Benelli, B., \& Altoe, G. (2008). Determinants of adolescents' active defending and passive bystanding behavior in bullying. Journal of Adolescence, 31, 93-105.

Gini, G., Pozzoli, T., Borghi, F., \& Franzoni, L. (2008). The role of bystanders in students' perception of bullying and sense of safety. Journal of School Psychology, 46, 617-638.

Goossens, F. A., Olthof, T., \& Dekker, P. (2006). New participant role scales: Comparison between various criteria for assigning roles and indications for their validity. Aggressive Behavior, 32, 343-357.

Graham, S., \& Hoehn, S. (1995). Children's understanding of aggression and withdrawal as social stigmas: An attributional analysis. Child Development, 66, 1143-1161. 
Greene, J. D., Nystrom, L. E., Engell, A. D., Darley, J. M., \& Cohen, J. D. (2004). The neural bases of cognitive conflict and control in moral judgment. Neuron, 44, 389-400.

Greenwald, A. G., \& Banaji, M. R. (1995). Implicit social cognition: Attitudes, self-esteem, and stereotypes. Psychological Review, 102, 4-27.

Hamlin, J. K. (2013). Moral judgment and action in preverbal infants and toddlers: Evidence for an innate moral core. Current Directions in Psychological Science, 22, 186-193.

Hara, H. (2002). Justifications for bullying among Japanese schoolchildren. Asian Journal of Social Psychology, 5, 197-204.

Hodges, E. V. E., \& Perry, D. G. (1999). Personal and interpersonal antecedents and consequences of victimization by peers. Journal of Personality and Social Psychology, 76, 677-685.

Huitsing, G., Snijders, T. A. B., van Duijn, M. A. J., \& Veenstra, R. (2014). Victims, bullies, and their defenders: A longitudinal study of the co-evolution of positive and negative networks. Development and Psychopathology, 26, 645-659.

Huitsing, G., \& Veenstra, R. (2012). Bullying in classrooms: Participant roles from a social network perspective. Aggressive Behavior, 38, 494-509.

Hymel, S., Schonert-Reichl, K. A., Bonanno, R. A., Vaillancourt, T., \& Rocke Henderson, N. (2010). Bullying and morality: Understanding how good kids can behave badly. In S. Jimerson, S. M. Swearer, \& D. L. Espelage (Eds.), International handbook of school bullying: An international perspective (pp. 101-118). New York: Routledge.

Ito, T. A., Larsen, J. T., Smith, N. K., \& Cacioppo, J. T. (1998). Negative information weighs more heavily on the brain: The negativity bias in evaluative categorizations. Journal of Personality and Social Psychology, 75, 887-900.

Juvonen, J., \& Galván, A. (2008). Peer influence in involuntary social groups: Lessons from research on bullying. In M. J. Prinstein \& K. A. Dodge (Eds.), Understanding peer influence in children and adolescents (pp. 225-244). New York: Guilford.

Kaltiala-Heino, R., Rimpelä, M., Rantanen, P., \& Rimpelä, A. (2000). Bullying at school: An indicator of adolescents at risk for mental disorders. Journal of Adolescence, 23, 661-674.

Kärnä, A., Voeten, M., Little, T. D., Poskiparta, E., Kaljonen, A., \& Salmivalli, C. (2011). A large-scale evaluation of the KiVa antibullying program: Grades 4-6. Child Development, 82, 311-330.

Krause, S., Back, M. D., Egloff, B., \& Schmukle, S. C. (2014). Implicit interpersonal attraction in small groups. Social Psychological and Personality Science, 5, 671-679.

Lansu, T. A. M., Cillessen, A. H. N., \& Bukowski, W. M. (2013). Implicit and explicit peer evaluation: Associations with early adolescents' prosociality, aggression, and bullying. Journal of Research on Adolescence, 23, 762-771.

Lansu, T. A. M., Cillessen, A. H. N., \& Karremans, J. C. (2012). Implicit associations with popularity in early adolescence: An approach-avoidance analysis. Developmental Psychology, 48, 65-75.

McConnell, A. R., \& Leibold, J. M. (2001). Relations among the implicit association test, discriminatory behavior, and explicit measures of racial attitudes. Journal of Experimental Social Psychology, 37, 435-442.

Menesini, E., Eslea, M., Smith, P. K., Genta, M. L., Giannetti, E., Fonzi, A., \& Costabile, A. (1997). Cross-national comparison of children's attitudes towards bully/victim problems in school. Aggressive Behavior, 23, 245-257.

Nansel, T. R., Overpeck, M., Pilla, R. S., Ruan, W., Simons-Morton, B., \& Scheidt, P. (2001). Bullying behaviors among US youth: Prevalence and association with psychosocial adjustment. Journal of the American Medical Association, 285, 2094-2100.

Olson, M. A., \& Fazio, R. H. (2009). Implicit and explicit measures of attitudes: The perspective of the MODE model. In R. H. Petty, R. H. Fazio, \& P. Brinol (Eds.), Attitudes: Insights from the new implicit measures (pp. 19-63). New York: Psychology Press.

Olthof, T., \& Goossens, F. A. (2008). Bullying and the need to belong: Early adolescents' bullying-related behavior and the acceptance they desire and receive from particular classmates. Social Development, 17, 24-46.

Olweus, D. (1994). Bullying at school: Basic facts and effects of a school based intervention program. Journal of Child Psychology and Psychiatry, 35, 1171-1190.

Onderwijs in Cijfers (2014). Leerlingenaantallen voortgezet onderwijs. Retrieved on May 26, 2015, from <http://www. onderwijsincijfers.nl/kengetallen/voortgezet-onderwijs/deelnemersvo/leerlingen-aantallen>.

Peeters, M., Cillessen, A. H. N., \& Scholte, R. H. J. (2010). Clueless or powerful? Identifying subtypes of bullies in adolescence. Journal of Youth and Adolescence, 39, 1041-1052.

Pellegrini, A. D., Bartini, M., \& Brooks, F. (1999). School bullies, victims, and aggressive victims: Factors relating to group affiliation and victimization in early adolescence. Journal of Educational Psychology, 91, 216-224.

Pouwels, J. L., Lansu, T. A. M., \& Cillessen, A. H. N. (2016). Participant roles of bullying in adolescence: Status characteristics, social behavior, and assignment criteria. Aggressive Behavior, 42, 239-253.

Pöyhönen, V., Juvonen, J., \& Salmivalli, C. (2010). What does it take to stand up for the victim of bullying? The interplay between personal and social factors. Merrill-Palmer Quarterly, 56, 143-163.

Reijntjes, A., Kamphuis, J. H., Prinzie, P., \& Telch, M. J. (2010). Peer victimization and internalizing problems in children: A metaanalysis of longitudinal studies. Child Abuse E Neglect, 34, 244-252.

Reijntjes, A., Vermande, M., Olthof, T., Goossens, F. A., van de Schoot, R., Aleva, L., \& van der Meulen, M. (2013). Costs and benefits of bullying in the context of the peer group: A three wave longitudinal analysis. Journal of Abnormal Child Psychology, 41, $1217-1229$.

Rigby, K. (2004). Addressing bullying in schools: Theoretical perspectives and their implications. School Psychology International, $25,287-300$.

Rigby, K. (2005). Why do some children bully at school? The contributions of negative attitudes towards victims and the perceived expectations of friends, parents and teachers. School Psychology International, 26, 147-161.

Rigby, K., \& Slee, P. T. (1991). Bullying among Australian school children: Reported behavior and attitudes toward victims. Journal of Social Psychology, 131, 615-627.

Rosen, P. J., Milich, R., \& Harris, M. J. (2007). Victims of their own cognitions: Implicit social cognitions, emotional distress, and peer victimization. Journal of Applied Developmental Psychology, 28, 211-226.

Salmivalli, C. (2010). Bullying and the peer group: A review. Aggression and Violent Behavior, 15, 112-120.

Salmivalli, C., Huttunen, A., \& Lagerspetz, K. M. J. (1997). Peer networks and bullying in schools. Scandinavian Journal of Psychology, 38, 305-312.

Salmivalli, C., Kaukiainen, A., \& Voeten, M. (2005). Anti-bullying intervention: Implementation and outcome. British Journal of Educational Psychology, 75, 465-487. 
Salmivalli, C., Lagerspetz, K., Björkqvist, K., Österman, K., \& Kaukiainen, A. (1996). Bullying as a group process: Participant roles and their relations to social status within the group. Aggressive Behavior, 22, 1-15.

Salmivalli, C., \& Voeten, M. (2004). Connections between attitudes, group norms, and behaviour in bullying situations. International Journal of Behavioral Development, 28, 246-258.

Scholte, R., Sentse, M., \& Granic, I. (2010). Do actions speak louder than words? Classroom attitudes and behavior in relation to bullying in early adolescence. Journal of Clinical Child E Adolescent Psychology, 39, 789-799.

Schuster, B. (2001). Rejection and victimization by peers: Social perception and social behavioral mechanisms. In J. Juvonen \& S. Graham (Eds.), Peer harassment in school: The plight of the vulnerable and victimized (pp. 290-309). New York: Guilford.

Smith, P. K., \& Ananiadou, K. (2003). The nature of school bullying and the effectiveness of school-based interventions. Journal of Applied Psychoanalytic Studies, 5, 189-209.

Solberg, M. E., \& Olweus, D. (2003). Prevalence estimation of school bullying with the Olweus Bully/Victim Questionnaire. Aggressive Behavior, 29, 239-268.

Stone, J., \& Fernandez, N. C. (2008). To practice what we preach: The use of hypocrisy and cognitive dissonance to motivate behavior change. Social and Personality Psychology Compass, 2, 1024-1051.

Strack, F., \& Deutsch, R. (2004). Reflective and impulsive determinants of social behavior. Personality and Social Psychology Review, 8, 220-247.

Teräsahjo, T., \& Salmivalli, C. (2003). "She is not actually bullied": The discourse of harassment in student groups. Aggressive Behavior, 29, 134-154.

Ttofi, M. M., \& Farrington, D. P. (2011). Effectiveness of school-based programs to reduce bullying: A systematic and metaanalytic review. Journal of Experimental Criminology, 7, 27-56.

Vaillancourt, T., \& Hymel, S. (2006). Aggression and social status: The moderating roles of sex and peer-valued characteristics. Aggressive Behavior, 32, 396-408.

Vaillancourt, T., Hymel, S., \& McDougall, P. (2003). Bullying is power: Implications for school-based intervention strategies. Journal of Applied School Psychology, 19, 157-176.

van Bakel, H. J. A., \& Riksen-Walraven, J. M. (2002). Parenting development of one-year-olds: Links with parental, contextual, and child characteristics. Child Development, 73, 256-273.

van Goethem, A. A. J., Scholte, R. H. J., \& Wiers, R. W. (2010). Explicit and implicit bullying attitudes in relation to bullying behavior. Journal of Abnormal Child Psychology, 38, 829-842.

van Noorden, T. H. J., Haselager, G. J. T., Cillessen, A. H. N., \& Bukowski, W. M. (2015). Empathy and involvement in bullying in children and adolescents: A systematic review. Journal of Youth and Adolescence, 44, 637-657. 